Research article

\title{
GnRH and LHR gene variants predict adverse outcome in premenopausal breast cancer patients
}

\author{
Djura Piersma ${ }^{1}$, Axel PN Themmen ${ }^{1}$, Maxime P Look², Jan GM Klijn², John A Foekens², \\ André G Uitterlinden ${ }^{1,3}$, Huibert AP Pols ${ }^{1,3}$ and Els MJJ Berns ${ }^{2}$
}

\author{
${ }^{1}$ Department of Internal Medicine, Erasmus MC, 3000 CA Rotterdam, The Netherlands \\ 2Department of Medical Oncology, Erasmus MC, 3000 CA Rotterdam, The Netherlands \\ ${ }^{3}$ Department of Epidemiology and Biostatistics, Erasmus MC, 3000 CA Rotterdam, The Netherlands
}

Corresponding author: Els MJJ Berns, p.berns@erasmusmc.nl

Received: 17 Apr 2007 Revisions requested: 15 May 2007 Revisions received: 30 Jul 2007 Accepted: 10 Aug 2007 Published: 10 Aug 2007

Breast Cancer Research 2007, 9:R51 (doi:10.1186/bcr1756)

This article is online at: http://breast-cancer-research.com/content/9/4/R51

(c) 2007 Piersma et al.; licensee BioMed Central Ltd.

This is an open access article distributed under the terms of the Creative Commons Attribution License (http://creativecommons.org/licenses/by/2.0), which permits unrestricted use, distribution, and reproduction in any medium, provided the original work is properly cited.

\begin{abstract}
Background Breast cancer development and progression are dependent on estrogen activity. In premenopausal women, estrogen production is mainly regulated through the hypothalamic-pituitary-gonadal (HPG) axis.

Methods We have investigated the prognostic significance of two variants of genes involved in the HPG-axis, the GnRH (encoding gonadotropin-releasing hormone) 16Trp/Ser genotype and the LHR (encoding the luteinizing hormone receptor) ins $L Q$ variant, in retrospectively collected premenopausal breast cancer patients with a long follow-up (median follow-up of 11 years for living patients).
\end{abstract}

Results Carriership was not related with breast cancer risk (the case control study encompassed 278 premenopausal cases and 1,758 premenopausal controls). A significant adverse relationship of the $L H R$ ins $L Q$ and $G n R H 16$ Ser genotype with disease free survival (DFS) was observed in premenopausal (hormone receptor positive) breast cancer patients. In particular, those patients carrying both the GnRH 16Ser and LHR insLQ allele (approximately 25\%) showed a significant increased risk of relapse, which was independent of traditional prognostic factors (hazard ratio $2.14 ; 95 \%$ confidence interval 1.32 to 3.45; $P=0.002)$.

Conclusion We conclude that the $L H R$ ins $L Q$ and $G n R H$ $16 S e r$ alleles are independently associated with shorter DFS in premenopausal patients. When validated, these findings may provide a lead in the development of tailored treatment for breast cancer patients carrying both polymorphisms.

\section{Introduction}

The diagnosis of breast cancer is made one million times each year worldwide. About one-quarter of these women are premenopausal at time of diagnosis, which is associated with poor prognosis compared to postmenopausal women $[1,2]$. It is anticipated that, as a result of changing demographic and lifestyle factors, more and more women will be diagnosed at a younger age with breast cancer $[3,4]$. In addition to age and family history, several factors relating to increased or prolonged cumulative estrogen exposure have been identified as important risk factors for breast cancer development and progression $[5,6]$. Polymorphic variation in genes regulating estrogen production may partly explain differences in suscep- tibility, clinical presentation and outcome of breast cancer between individuals or populations $[6,7]$.

In premenopausal women, estrogens predominantly arise from the ovaries, where production is regulated by the neuro-endocrine system consisting of hypothalamus, pituitary and gonads: the HPG axis. Internal and external stimuli are integrated in the brain, resulting in the pulsatile secretion of the hypothalamic neuropeptide gonadotropin-releasing hormone $(\mathrm{GnRH}) . \mathrm{GnRH}$ reaches the gonadotroph cells in the anterior pituitary through the hypophysial portal circulation, where it stimulates de novo synthesis and secretion of the gonadotropins follicle stimulating hormone and luteinizing hormone (LH),

$\mathrm{Cl}=$ confidence interval; $\mathrm{df}=$ degrees of freedom; $\mathrm{DFS}=$ disease free survival; $\mathrm{ER}=$ estrogen receptor; $\mathrm{GnRH}=$ gonadotropin-releasing hormone; $\mathrm{HPG}=$ hypothalamic-pituitary-gonadal; $\mathrm{HR}=$ hazard ratio; $\mathrm{HWE}=$ Hardy-Weinberg equilibrium; ins $\mathrm{LQ}=$ insertion Leu-Gln; $\mathrm{LH}=$ luteinizing hormone; $\mathrm{LHR}=$ luteinizing hormone receptor; SNP = single nucleotide polymorphism. 
which reach the ovaries in women through the circulation. $\mathrm{LH}$, acting through the $\mathrm{LH}$ receptor (LHR), stimulates production of androgen precursors in theca cells that surround antral follicles. Follicle stimulating hormone subsequently regulates the granulosa cell enzyme aromatase, which converts these androgens to estrogens. In turn, ovarian sex steroid and peptide hormones (inhibin $A$ and $B$ ) provide negative feedback regulation, either in the pituitary or hypothalamus. The menopausal transition, that is, the cessation of menstrual cycling, is characterized by disruption of this tightly balanced HPG axis system and is accompanied by continuously increased serum $\mathrm{LH}$ and follicle stimulating hormone in combination with decreased levels of ovarian sex steroid hormones $[8,9]$.

We have previously reported, in a training set of 266 Australian breast cancer patients, an association between a common polymorphic CTCCAG (Leu-Gln (LQ)) insertion ( $L H R$ ins LQ) in the signal peptide of the $L H R$ gene and poor survival [10]. No associations between its ligand, LH, genotype and clinical parameters were observed in this study. In our subsequent validation study on a large independent breast cancer cohort of 751 retrospectively collected Dutch patients with long detailed follow-up, we have confirmed the association of the $L H R$ ins $L Q$ gene variant with a shorter disease-free survival (DFS) [11]. Furthermore, we have shown the functional importance of the LQ insertion in the signal peptide, that is, an increased activity for the LHR insLQ variant compared with the LHR non-LQ protein. We hypothesized an ovary-dependent increase in cumulative estrogen exposure that may influence breast cancer outcome in patients with the LHR ins $L Q$ genotype [10]. Interestingly, the $G n R H$ gene also carries a common signal peptide polymorphism (Trp16Ser) [12], which has been associated with altered bone mineral density, an indirect marker for estrogen exposure [13].

In line with the hypothesis that possible associations of the above mentioned polymorphisms with outcome would depend on HPG-regulation of ovarian function, we have investigated associations of the $L H R$ ins $L Q$ and $G n R H 16$ Ser alleles with premenopausal breast cancer outcome in the present study.

We observed that hormone receptor positive premenopausal women carrying either of the variant alleles or the combined variant alleles of both genes had a significant shorter DFS; $L H R$ ins $L Q$ and the combined alleles were independent of traditional prognostic factors.

\section{Materials and methods Breast tumor samples}

The study design was approved by the Medical Ethics Committee of the Erasmus MC, Rotterdam, the Netherlands. From the DNA samples with complete follow up described previously [11], we have included 278 premenopausal patients with known estrogen receptor (ER) status, conclusive geno- types and complete follow up. All tumors were invasive (42 had an additional in situ component).

The menopausal status of patients was determined according to the guidelines of the European Organization of Research and Treatment of Cancer (EORTC). The median age of patients at diagnosis was 45 years (range 22 to 57 years). The median follow-up period of all patients was 112 months (range 9 to 255 months) and of still living patients 130 months from primary surgery (range 13 to 255 months). Pathological examination was not performed centrally and reflects daily practice in the various participating regional hospitals as described previously. Other patient characteristics are listed in Table 1.

\section{Control population}

As a control cohort we studied banked blood samples of preand perimenopausal women from the Eindhoven Perimenopausal Osteoporosis Study (EPOS). The EPOS study is a population-based cohort study of pre-, peri- and postmenopausal women born between 1941 and 1947 living in the city of Eindhoven, The Netherlands (median age 50.0 years (range 46 to 57 years)). The study rationale and design have been described previously [14]. Participants gave their written informed consent, and the study was approved by the Medical Ethics Committee of the Erasmus MC, Rotterdam. For the present study we included 1,758 (successful genotyping for the $L H R$ as well as $G n R H$ genotypes) pre- and perimenopausal subjects, after excluding women with a history of breast carcinoma. All subjects (median age 49.5 years) are of Caucasian Dutch descent. Data for baseline examination and blood samples for extracting DNA from peripheral leucocytes were collected between 1994 and 1995.

\section{Genotyping}

High molecular weight genomic DNA was used as a template for PCR amplification. Exon 1 of the LHR gene was amplified as described by Atger and colleagues [15] using a 5'-hexachlorofluorescein labeled forward primer. Separation and sizing of the PCR fragments and assignment of $L H R$ ins $L Q$ genotype was performed using the ABI Prism 3100 automated capillary DNA sequencer and Genescan and Genotyper software packages (Applied Biosystems, Perkin Elmer, Nieuwerkerk aan den IJssel, The Netherlands) as described by us before [11].

The 16Trp/Ser polymorphism in the GnRH gene was determined using the Taqman allelic discrimination assay. Primer sequences used for amplification of the fragment of exon 1, including the single nucleotide polymorphism (SNP) were AATTCAAAAACTCCTAGCTGGCCTTA (forward) and CATAGGACCAGTGCTGGCT (reverse). Used probes (with SNP underlined) were 5'-VIC-CACGCACㅡAAGTCA (anti-sense) and 5'-FAM-AGCCACGAAGTCA (anti-sense). Primer and probe sequences were optimized using the SNP assay-bydesign service of Applied Biosystems (for details, see [16]). 
Table 1

\begin{tabular}{|c|c|c|c|c|c|c|c|}
\hline \multirow[b]{2}{*}{ Feature } & \multirow[b]{2}{*}{$\begin{array}{l}\text { Number } \\
\text { (percent) }\end{array}$} & \multicolumn{2}{|c|}{ LHR ins $L Q$} & \multirow[b]{2}{*}{$P$ value $^{a}$} & \multicolumn{2}{|c|}{ GnRH 16Ser } & \multirow[b]{2}{*}{$P$ value $^{\mathrm{a}}$} \\
\hline & & $\begin{array}{l}\text { Non-carriers } \\
\text { (percent) }\end{array}$ & $\begin{array}{c}\text { Carriers } \\
\text { (percent) }\end{array}$ & & $\begin{array}{l}\text { Non-carriers } \\
\text { (percent) }\end{array}$ & $\begin{array}{c}\text { Carriers } \\
\text { (percent) }\end{array}$ & \\
\hline Breast cancer cases & $278(100)$ & $147(53)$ & $131(47)$ & & $157(56)$ & $121(44)$ & \\
\hline Age in years & & & & 0.18 & & & 0.56 \\
\hline$<35$ & $19(7)$ & 12 & 7 & & 9 & 10 & \\
\hline $35-39$ & $35(12)$ & 13 & 22 & & 17 & 18 & \\
\hline $40-49$ & $167(60)$ & 93 & 74 & & 99 & 68 & \\
\hline $50-59$ & $57(21)$ & 29 & 28 & & 32 & 25 & \\
\hline Node status & & & & 0.78 & & & $0.001^{b}$ \\
\hline Negative & $134(48)$ & 72 & 62 & & 89 & 45 & \\
\hline Positive & $144(52)$ & 75 & 69 & & 68 & 76 & \\
\hline Histological grade ${ }^{c}$ & & & & 0.04 & & & 0.15 \\
\hline Well/mod & $66(24)$ & 44 & 22 & & 41 & 25 & \\
\hline unknown & $59(21)$ & 28 & 31 & & 27 & 32 & \\
\hline Poor & $153(55)$ & 75 & 78 & & 89 & 64 & \\
\hline Tumor size & & & & 0.58 & & & 0.30 \\
\hline$\leq 2 \mathrm{~cm}$ & $113(41)$ & 62 & 51 & & 68 & 45 & \\
\hline$>2 \mathrm{~cm}$ & $165(59)$ & 85 & 80 & & 89 & 76 & \\
\hline Estrogen receptor status ${ }^{c, e}$ & & & & 0.095 & & & 0.29 \\
\hline Negative & $78(28)$ & 35 & 43 & & 48 & 30 & \\
\hline Positive & $200(72)$ & 112 & 88 & & 109 & 91 & \\
\hline Progesterone receptor status $\mathrm{s}^{\mathrm{c}, \mathrm{e}}$ & & & & 0.15 & & & $0.54^{f}$ \\
\hline Negative & $70(25)$ & 32 & 38 & & 42 & 28 & \\
\hline Positive & $199(72)$ & 111 & 88 & & 111 & 88 & \\
\hline HER2 amplifiedc & & & & 0.68 & & & 0.85 \\
\hline Yes & $55(20)$ & 28 & 27 & & 30 & 25 & \\
\hline No & $202(73)$ & 106 & 96 & & 114 & 88 & \\
\hline Adjuvant therapy & & & & 0.54 & & & 0.09 \\
\hline No & $158(57)$ & 88 & 70 & & 96 & 62 & \\
\hline Hormonal & $4(1)$ & 1 & 3 & & 1 & 3 & \\
\hline Chemotherapy & $110(40)$ & 55 & 55 & & 55 & 55 & \\
\hline Combined & $6(2)$ & 3 & 3 & & 5 & 1 & \\
\hline
\end{tabular}

${ }^{a} \chi^{2}$ test. ${ }^{b}$ Also, when stratified per 'genotype', $P=0.003$. cNumbers in cells may not add up due to incomplete information on histological grade and/or receptor status. dTumors of unknown size $(n=10)$ are included as tumor size $>2 \mathrm{~cm}$. eThe cutoff value used was $10 \mathrm{fmol} / \mathrm{mg} \mathrm{protein.}$

fSignificant when stratified per 'genotype', $P=0.02$. Entries in bold represent significant outcomes.

These reactions were performed on the Taqman Prism 7900 HT 384 wells format. Snap frozen primary breast cancer specimens, stored in liquid nitrogen and from which the DNA was obtained for genotyping, contain a relatively high proportion $(>40 \%)$ of non-tumor tissue. This ensures accurate genotyping, irrespective of the possible loss of heterozygosity that may occur in tumor tissue [10]. Furthermore, to test for possible loss of heterozygosity we have examined the Hardy-Weinberg equilibrium (HWE). 


\section{Statistical analysis}

Pearson's $\chi^{2}$ analysis and Fisher's exact test were used to test for independence of the alleles (HWE) and for association analyses with patient and tumor characteristics, respectively. We allowed for three possible genetic models to explain differences in patient and tumor characteristics between genotype groups: linear, dominant or recessive effects. A linear effect, assuming a dose-response relationship of the association for the presence of zero, one or two copies of the allele, was tested using a $\left(\chi^{2}\right)$ linear trend analysis [17]. A dominant effect between hetero- and homozygous combined carriers versus non-carriers was tested using $\chi^{2}$ analysis. Indications for recessive effects were not observed. Univariate and multivariate DFS analyses (endpoint: recurrence excluding second primary breast tumor) were carried out using Cox proportional hazards regression analysis. Hazard ratios (HRs) for the $L H R$ ins $L Q$ and $G n R H 16 S e r$ alleles are presented with their $95 \%$ confidence interval $(\mathrm{Cl})$. Differences between HRs per $L H R$ ins $L Q$ and $G n R H$ 16Ser genotype were tested using the likelihood ratio test associated with the Cox regression analysis. In multivariate analysis, Cox proportional hazard models for DFS were applied to test the genotype variables against traditional factors using a forward stepwise model. The multivariate model included age, positive versus negative nodal status, differentiation grade, tumor size (larger tumors versus tumors $\leq 2$ $\mathrm{cm})$, ER status and adjuvant therapy. DFS curves were generated using the actuarial method of Kaplan-Meier [18] and logrank tests were used to test for equality of survival functions. All computations were carried out using the STATA statistical package, version 9.2 (Stata Corp., College Station, TX, USA). Statistical significance was assumed at $P \leq 0.05 ; P$ values are two-tailed and relate to data during the total period of followup.

\section{Results}

\section{LHR ins $L$ and GnRH 16Trp/Ser genotyping}

Genotype analysis for the $L H R$ ins $L Q$ polymorphism in the 278 premenopausal patients studied revealed an allele frequency of 0.27 . This resulted in 147 (52.9\%) nonLQ/nonLQ homozygotes, $113(40.7 \%)$ heterozygotes and $18(6.5 \%)$ ins $L Q$ /ins $L Q$ homozygotes. The allele frequency for the $\mathrm{GnRH}$ $16 \mathrm{Ser}$ polymorphism was 0.25 . The genotype distribution was 157 (56.5\%) 16Trp/16Trp homozygotes, 103 (37.1\%) heterozygotes and $18(6.5 \%)$ 16Ser/16Ser homozygotes. Both genotypes were found to be in $\operatorname{HWE}(P=0.55$ and $P=0.84$, respectively). The genotype distributions and allele frequencies in the control cohort from the EPOS study $(n=1,758)$, did not differ significantly from the case distributions. Genotype results for the $L H R$ ins $L Q$ polymorphism revealed an allele frequency of 0.29 . The genotype distribution was 901 (51.3\%) nonLQ/nonLQ homozygotes, 708 (40.3\%) heterozygotes and 149 (8.5\%) insLQ/insLQ homozygotes. Genotyping for the $\mathrm{GnRH} 16 \mathrm{Ser}$ allele resulted in an allele frequency of 0.25 and revealed 1,004 (57.1\%) 16Trp/16Trp homozygotes, 627 (35.7\%) heterozygotes and 127 (7.2\%) 16Ser/
16Ser homozygotes, in HWE. All genotype frequencies and allele frequencies are closely similar in the cases series and in the population controls, which lends support to the genotyping results in tumor material. We conclude that neither $L H R$ ins $L Q$ nor $G n R H 16 S e r$ genotypes influence the risk of breast cancer development.

\section{Associations with patient and tumor characteristics}

The distribution of clinico-pathological characteristics across the GnRH 16Trp/Ser genotype showed a dominant effect of presence of the $\mathrm{GnRH} 16 \mathrm{Ser}$ allele. Carriers of the $\mathrm{GnRH}$ $16 \mathrm{Ser}$ allele were, therefore, compared to non-carriers. Carriership of the $\mathrm{GnRH} 16 \mathrm{Ser}$ allele was significantly associated with increased lymph node involvement $(P=0.001)$, while $\mathrm{GnRH}$ genotype was associated with progesterone receptor levels $(P=0.02)$. $L H R$ ins $L Q$ was associated with histological grade. Both polymorphisms were not significantly associated with other clinico-pathological characteristics. No significant interaction between the presence of the $L H R$ ins $L Q$ and $\mathrm{GnRH} 16 \mathrm{Ser}$ variants was observed in these association analyses.

\section{Associations of $L H R$ ins $L Q$ and GnRH 16Ser variants with DFS}

We hypothesized that HPG-mediated increases in cumulative ovarian estrogen exposure influence breast cancer outcome. The adverse association of the $L H R$ ins $L Q$ allele with DFS was observed in the premenopausal patients (HR for carriers versus non-carriers $=1.59,95 \% \mathrm{Cl} 1.14$ to $2.23, P=0.007$; Table 2). In these premenopausal patients the $L H R$ ins $L Q$ genotype was an independent prognostic factor: addition of LHR ins $L Q$ carriership to the multivariate model resulted in an increase of $\chi^{2}$ from 44.06 to $52.23\left(\Delta \chi^{2}=8.17(\mathrm{df}=1), P=\right.$ $0.004)$ for DFS. The association between the presence of the GnRH 16Ser allele and DFS was also tested. An increased HR of 1.40 (95\% Cl 1.00 to $1.96, P=0.05$; Table 2) for $\mathrm{GnRH} 16 \mathrm{Ser}$ carriers versus non-carriers was observed.

Interestingly, in the biological relevant hormone receptor subgroup (ER and/or progesterone receptor positive, $n=225$ $(81 \%))$, the $L H R$ ins $L Q$ genotype retained significance. The adverse association of the $L H R$ ins $L Q$ allele with DFS had a HR for carriers versus non-carriers of 1.59 (95\% Cl 1.11 to $2.28, P=0.012$ ). It was also an independent prognostic factor: addition of $L H R$ ins $L Q$ carriership to the multivariate model resulted in an increase of $\chi^{2}$ from 36.28 to $42.70\left(\Delta \chi^{2}\right.$ $=6.42(\mathrm{df}=1), P=0.01)$ for DFS. Moreover, the association between the presence of the GnRH 16Ser allele and DFS revealed a significantly increased HR of $1.44(95 \% \mathrm{Cl} 1.01$ to 2.07, $P=0.046)$. In multivariate analysis for $\mathrm{GnRH} 16 \mathrm{Ser}$ carriers versus non-carriers this was not significant.

\section{Cooperative effect of variants on the HPG axis and DFS}

The HPG system in the premenopausal woman involves a cooperative effect of both $\mathrm{GnRH}$ and $\mathrm{LH}$ action on the 
Table 2

Cox univariate and multivariate analysis for disease free survival in the 278 premenopausal breast cancer patients

\begin{tabular}{|c|c|c|c|c|c|c|c|c|}
\hline \multirow[b]{2}{*}{ Factor of base model } & \multicolumn{2}{|c|}{ Patients } & \multicolumn{3}{|c|}{ Univariate analysis } & \multicolumn{3}{|c|}{ Multivariate analysis } \\
\hline & Number & Percent & $\mathrm{HR}$ & 95 percent $\mathrm{Cl}$ & $P$ value & HR & 95 percent $\mathrm{Cl}$ & $P$ value \\
\hline \multicolumn{9}{|l|}{ Age (years) } \\
\hline$<39$ & 54 & 24 & 1.00 & & & 1.00 & & \\
\hline $40-49$ & 167 & 60 & 0.72 & $0.50-1.06$ & & 0.66 & $0.44-0.98$ & \\
\hline $50-59$ & 57 & 21 & 0.42 & $0.23-0.77$ & 0.013 & 0.35 & $0.19-0.67$ & $<0.001$ \\
\hline \multicolumn{9}{|l|}{ Nodal status } \\
\hline Negative & 134 & 48 & 1.00 & & & 1.00 & & \\
\hline Positive & 144 & 52 & 1.90 & $1.34-2.70$ & $<0.001$ & 3.68 & $2.11-6.42$ & $<0.001$ \\
\hline \multicolumn{9}{|l|}{ Histological grade } \\
\hline Poor & 153 & 55 & 1.00 & & & 1.00 & & \\
\hline Unknown & 59 & 21 & 0.51 & $0.32-0.83$ & & 0.54 & $0.33-0.88$ & \\
\hline Well/moderate & 66 & 24 & 0.55 & $0.36-0.85$ & 0.002 & 0.56 & $0.35-0.88$ & 0.019 \\
\hline \multicolumn{9}{|l|}{ Tumor size } \\
\hline$\leq 2 \mathrm{~cm}$ & 113 & 41 & 1.00 & & & 1.00 & & \\
\hline$>2 \mathrm{~cm}$ & 165 & 59 & 1.77 & $1.23-2.54$ & 0.002 & 1.57 & $1.07-2.30$ & 0.021 \\
\hline \multicolumn{9}{|l|}{ Estrogen receptor status } \\
\hline Negative & 78 & 28 & 1.00 & & & 1.00 & & \\
\hline Positive & 200 & 72 & 0.87 & $0.60-1.27$ & 0.48 & 1.01 & $0.68-1.49$ & 0.96 \\
\hline \multicolumn{9}{|l|}{ Adjuvant therapy } \\
\hline No & 158 & 57 & 1.00 & & & 1.00 & & \\
\hline Yes $^{a}$ & 120 & 43 & 1.41 & $1.01-1.97$ & 0.045 & 0.41 & $0.24-0.70$ & 0.001 \\
\hline \multicolumn{9}{|l|}{ Factors analyzed } \\
\hline \multicolumn{9}{|l|}{ Carriership } \\
\hline Non-carriersb & & & 1.00 & & & 1.00 & & \\
\hline GnRH 16Ser & 121 & 44 & 1.40 & $1.00-1.96$ & 0.050 & 1.32 & $0.93-1.88$ & 0.12 \\
\hline LHR insLQ & 131 & 47 & 1.59 & $1.14-2.23$ & 0.007 & 1.64 & $1.16-2.32$ & 0.005 \\
\hline \multicolumn{9}{|l|}{ Combined carriership } \\
\hline Non-carriers & 87 & 31 & 1.00 & & & 1.00 & & \\
\hline Only GnRH 16Ser & 60 & 22 & 1.39 & $0.84-2.29$ & 0.19 & 1.24 & $0.74-2.08$ & 0.42 \\
\hline Only LHR insLQ & 70 & 25 & 1.59 & $0.99-2.54$ & 0.055 & 1.56 & $0.97-2.51$ & 0.067 \\
\hline LHR ins $L Q+G n R H 16 S e r$ & 61 & 22 & 2.17 & $1.36-3.48$ & 0.001 & 2.14 & $1.32-3.45$ & 0.002 \\
\hline
\end{tabular}

aOf 120 patients who received adjuvant therapy, 110 received chemotherapy (mainly CMF, $n=101$ ), 4 endocrine therapy, and 6 both; node negatives were not treated. bThe number of $G n R H 16 S e r$ non-carriers was 157, and of $L H R$ ins $L Q$ non-carriers was 147 patients.

regulation of ovarian sex steroid production. Therefore, we have examined in an exploratory study the combined effect of the $\mathrm{GnRH} 16 \mathrm{Ser}$ and $L H R$ ins $L Q$ variants in these premenopausal breast cancer patients. We combined heterozygous and homozygous carriers, providing four groups of similar sizes. Non-carriers, carriers of the GnRH 16Ser allele, carriers of the $L H R$ ins $L Q$ allele, and carriers of both alleles were compared.

The combination of both variants in premenopausal breast cancer patients, present in $22 \%$ of this group, resulted in a HR of 2.17 versus non-carriers of both variants $(95 \% \mathrm{Cl} 1.36$ to $3.48, P=0.001$; log-rank test for trend $P=0.001$; Figure $1 \mathrm{a}$ 
Figure 1
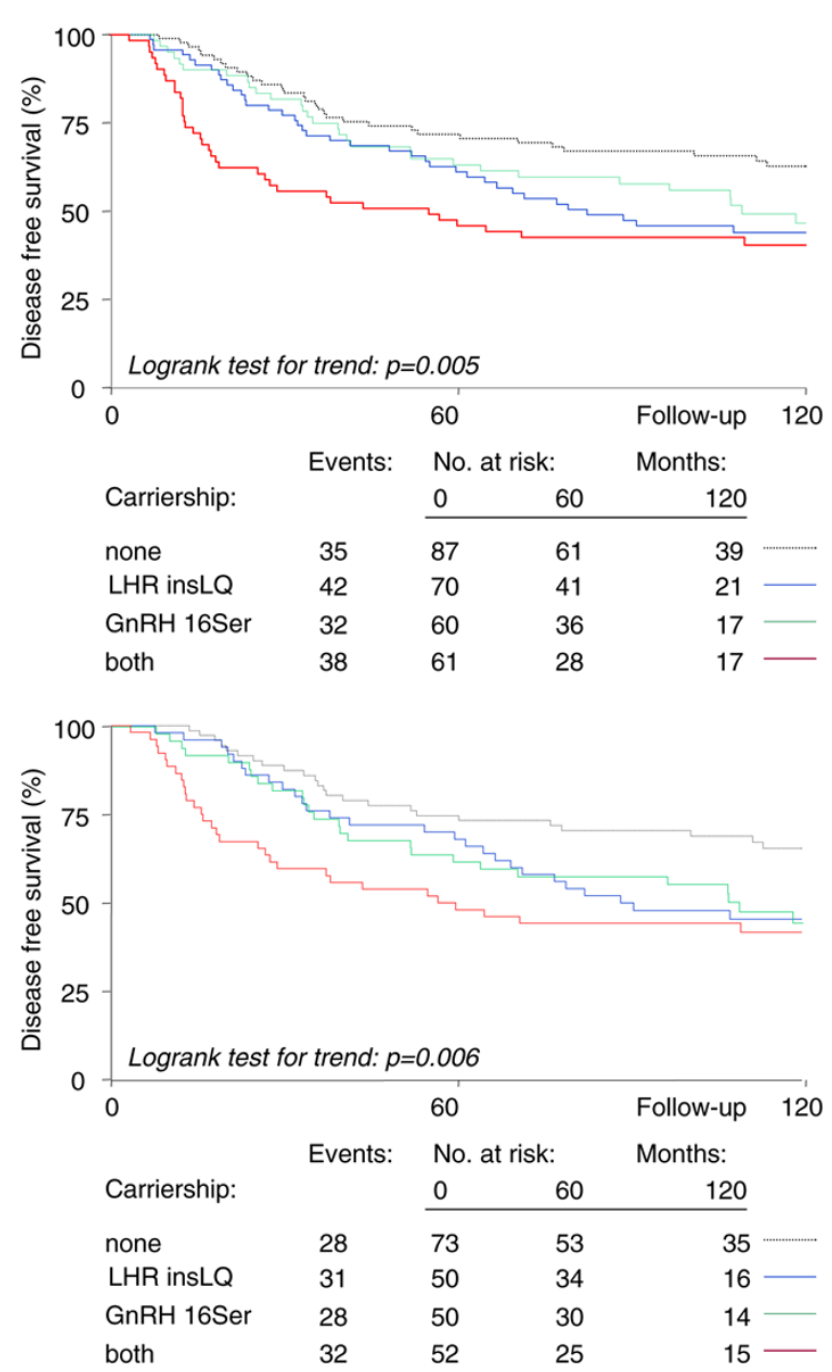

Relation of $G n R H$ and $L H R$ gene variants with disease-free survival. (a) Kaplan-Meier curves for disease free survival (DFS) comparing carriers versus non-carriers in all premenopausal breast cancer patients. DFS curves are depicted for carriers of LHR ins $L Q$ (blue), GnRH 16Ser (green) and both variants (red) versus non-carriers of both variants (gray dotted line). (b) Kaplan-Meier curves for DFS comparing carriers versus non-carriers in hormone receptor positive premenopausal breast cancer patients. DFS curves are depicted for carriers of $L H R$ ins $L Q$ (blue), GnRH 16Ser (green) and both variants (red) versus non-carriers of both variants (gray dotted line).

and Table 2). This HR is higher than that for HER2 amplified tumors (HR of $1.61,95 \% \mathrm{Cl} 1.09$ to $2.39, P=0.016$ ); HER2 is amplified in about $20 \%$ of the tumors. In multivariate analysis, including the prognostic factors age, nodal status, differentiation grade, tumor size, ER status, and adjuvant therapy, the association was independent: $\Delta \chi^{2}=10.0(\mathrm{df}=3), P=$ $0.018 ; \mathrm{HR}=2.14,95 \% \mathrm{Cl} 1.32$ to $3.45, P=0.002$. No significant interaction between the presence of the $L H R$ ins $L Q$ and $\mathrm{GnRH} 16 \mathrm{Ser}$ variants was observed in these survival analyses.
We next studied the effect in hormone receptor positive patients. The combination of both variants, present in 52 out of 225 patients of this group, resulted in a HR of 2.43 versus non-carriers of both variants $(95 \% \mathrm{Cl} 1.42$ to $4.18, P=$ 0.0013 ; log-rank test for trend $P=0.0055$; Figure $1 \mathrm{~b}$ ). In multivariate analysis, including the prognostic factors listed above, the association was independent: $\Delta \chi^{2}=8.72(\mathrm{df}=3), P=$ $0.03 ; \mathrm{HR}=2.06,95 \% \mathrm{Cl} 1.21$ to $3.49, P=0.007$. No significant interaction between the presence of the $L H R$ ins $L Q$ and $\mathrm{GnRH}$ 16Ser variants was observed in these survival analyses.

\section{Discussion}

Breast cancer is a heterogeneous and complex disease. Many gene variants, acting in concert with each other and with environmental factors, may influence its susceptibility, prognosis and response to treatment [19]. In light of their possible role in the variability of estrogen exposure, variants of genes involved in the HPG axis are likely candidates to contribute to differences in clinical phenotype and outcome. In the present study we tested this hypothesis. In a genetic association approach we used stratification for ovarian activity and explored cooperative action of two HPG gene variants. We show an association between the $L H R$ ins $L Q$ allele and shorter DFS in premenopausal patients, especially in the hormone receptor positive subset. A common $\mathrm{GnRH}$ gene variant, $\mathrm{GnRH} 16 \mathrm{Ser}$, showed an association with lymph node involvement. In addition, coincident carriership of the GnRH $16 \mathrm{Ser}$ and $L H R$ ins $L Q$ variants, present in almost one-quarter of the patients, resulted in a more than doubled risk of recurrence of disease in (hormone receptor positive) premenopausal patients with a long ( $>10$ years follow-up of still living patients). Multivariate analyses showed that these associations with poor DFS were independent of known prognostic factors.

Whether variants of the $G n R H$ gene differ in function remains to be elucidated. Substitution of Trp16 by the less hydrophobic serine may change the efficiency of the GnRH signal peptide. Using the same in vitro assay for the insLQ signal peptide variant, as described by us previously [11], we were unable to detect a difference in signal peptide efficiency between the $\mathrm{GnRH}$ 16Ser and GnRH 16Trp signal peptide constructs (data not shown). Furthermore, in silico analysis of the variants using the program SignalP 3.0 [20] did not result in any difference in signal peptide characteristics. On the other hand, Iwasaki and colleagues [13] have described an association between the GnRH 16Trp allele and higher bone mineral density, considered to be an indirect marker for estrogen activity, in 384 Japanese postmenopausal women; this suggests there is higher estrogen activity in women bearing this variant. In contrast, we observed a significant increased lymph node involvement and shorter DFS in Caucasian breast cancer patients carrying the other variant, the GnRH 16Ser allele, which we hypothesize to result from a higher level of cumulative estrogen exposure. Possible reasons for the apparent 
conflicting results are numerous, including differences in sample size, technical approach, and ethnicity, or so far unknown differences in the interaction of genetic and environmental factors between Japanese and Caucasian subjects. Consequently, further studies are needed to identify the exact mechanisms of the effect of the GnRH 16Ser polymorphism, including linkage to other polymorphisms in the $\mathrm{GnRH}$ gene that may affect regulation of expression.

There are several hypotheses as to how $G n R H$ and $L H R$ gene variants may affect tumor features and clinical outcome in breast cancer as demonstrated in this study. In view of the abundant data on the direct effects of $\mathrm{GnRH}$ modulation on sex steroid hormone-dependent cancers, a direct effect of locally produced $\mathrm{GnRH}$ via $\mathrm{GnRH}$ receptors expressed in breast cancer tissue cannot be ruled out [21-24]. Local coexpression of mRNAs for $\mathrm{GnRH}$ and the $\mathrm{GnRH}$ receptor in breast cancer tissue has been shown [25,26], and direct growth inhibition of cultured breast cancer cells have been reported as well [27]. However, to our knowledge, local production of $\mathrm{GnRH}$ has not been shown. Hypothalamic $\mathrm{GnRH}$ is unlikely to reach the breast via the peripheral circulation given its low concentration and short half-life [28]. Furthermore, the effects of $\mathrm{GnRH}$ agonist treatment regimens are most likely explained by down-regulation of pituitary $\mathrm{GnRH}$ receptors and subsequent shutdown of the HPG axis [29]. A few studies have shown LHR expression in normal and breast tumor cells. However, it is less likely that direct effects of $\mathrm{LH}$ explain the adverse association of $L H R$ ins $L Q$ with DFS, since this was not seen in the postmenopausal patients (data not shown) in whom circulating LH levels are high.

In premenopausal women, epithelial proliferation in the nonpregnant, non-lactating breast is maximal approximately one week after ovulation in the luteal phase of the menstrual cycle. During the luteal phase, which can be considered a risky period for carcinogenesis in the breast, the corpus luteum is the main site of estrogen and progesterone hormone production, which is, in large part, dependent on LHR action. Therefore, increased cyclic hormonal stimulation of early breast cancer in women carrying activating HPG gene variants may enhance dedifferentiation and worsen prognosis. In premenopausal breast cancer patients with advanced disease, reduction of estrogen levels by a $\mathrm{GnRH}$ agonist in combination with the ER antagonist tamoxifen improves clinical outcome compared with the use of $\mathrm{GnRH}$ agonists or tamoxifen alone $[29,30]$. Randomized trials assessing whether the combination of a GnRH agonist with an aromatase inhibitor as adjuvant therapy improves outcome compared to treatment consisting of a $\mathrm{GnRH}$ agonist and tamoxifen are ongoing [31]. Regimens for endocrine therapy are still largely empirically based [32]. Recently, it has been suggested that, as for adjuvant systemic therapy, the role of genetic factors in breast cancer treatment outcome should be considered [33]. Our current study identified almost $25 \%$ of premenopausal patients with a genetic background associated with clearly significant poor outcome and hypothetically associated with altered treatment outcomes. Exploratory studies in our subset of patients that received adjuvant endocrine therapy $(n=4)$ were too underpowered to detect differences in response. Finally, it can be hypothesized that the $\mathrm{GnRH}$ and LHR variants may play a role in chemotherapy-induced amennorhoea [33], since 110 of the patients studied were treated with chemotherapy. Although adjuvant chemotherapy was equally divided over patients with and without polymorphisms, possible differences in the chance of ovarian failure resulting from chemotherapy may bias the outcome. However, since chemotherapy is likely to inhibit ovarian activity, this is not anticipated.

\section{Conclusion}

We have shown a strong and independent association with DFS (HR = 2.1) in almost one-quarter of (hormone receptor positive) premenopausal women carrying $L H R$ ins $L Q$ and $\mathrm{GnRH} 16 \mathrm{Ser}$ genotypes. The observations strongly suggest that the adverse outcome in patients with these variants occurs through enhanced HPG-mediated ovarian estrogen production. Prospective studies, including serum estrogen analyses, are needed. When validated in independent studies, the observed results raise the possibility that $L H R$ ins $L Q$ and $\mathrm{GnRH} 16 \mathrm{Ser}$ genotyping may provide additional prognostic information for premenopausal breast cancer patients in clinical practice and may result in tailored endocrine treatments for these patients.

\section{Competing interests}

The authors declare that they have no competing interests.

\section{Authors' contributions}

DP was involved in the acquisition of the data and drafted the manuscript. APNT and EMJJB conceived and supervised the experimental work and helped draft the manuscript. MPL carried out all statistical analysis. AGU was involved in the acquisition of the data and the drafting of the manuscript. JGMK and JAF initiated the breast tumor specimen collection program and participated in discussions on project design. HAPP reviewed the manuscript and added important intellectual content to it. All authors participated in subsequent revisions of the manuscript and approved its final version.

\section{Acknowledgements}

The authors wish to thank Miriam Verhoef-Post, Iris L van Staveren, Kirsten Ritstier and Pascal Arp for technical assistance in DNA preparation and genotyping, Fernando Rivadeneira for assistance in data interpretation and Drs Sleijfer, Bontenbal, Visser and Siemes and Prof. Stricker for constructive discussions.

\section{References}

1. Chung M, Chang HR, Bland KI, Wanebo HJ: Younger women with breast carcinoma have a poorer prognosis than older women. Cancer 1996, 77:97-103.

2. Aebi S, Gelber S, Castiglione-Gertsch M, Gelber RD, Collins J, Thurlimann B, Rudenstam CM, Lindtner J, Crivellari D, CortesFunes $\mathrm{H}$, et al:: Is chemotherapy alone adequate for young 
women with oestrogen-receptor-positive breast cancer? Lancet 2000, 355:1869-1874.

3. Dellapasqua S, Colleoni M, Gelber RD, Goldhirsch A: Adjuvant endocrine therapy for premenopausal women with early breast cancer. J Clin Oncol 2005, 23:1736-1750.

4. SEER Cancer Statistics Review, 1975-2004 [http://seer.can cer.gov/csr/1975 2004

5. Clemons M, Goss P: Estrogen and the risk of breast cancer. $N$ Engl J Med 2001, 344:276-285.

6. Mitrunen K, Hirvonen A: Molecular epidemiology of sporadic breast cancer. The role of polymorphic genes involved in oestrogen biosynthesis and metabolism. Mutat Res 2003, 544:9-41.

7. Martin AM, Weber BL: Genetic and hormonal risk factors in breast cancer. J Natl Cancer Inst 2000, 92:1126-1135.

8. Weiss G, Skurnick JH, Goldsmith LT, Santoro NF, Park SJ: Menopause and hypothalamic-pituitary sensitivity to estrogen. JAMA 2004, 292:2991-2996.

9. Landgren BM, Collins A, Csemiczky G, Burger HG, Baksheev L, Robertson DM: Menopause transition: Annual changes in serum hormonal patterns over the menstrual cycle in women during a nine-year period prior to menopause. J Clin Endocrinol Metab 2004, 89:2763-2769.

10. Powell BL, Piersma D, Kevenaar ME, van Staveren IL, Themmen $A P$, lacopetta BJ, Berns EMJJ: Luteinizing hormone signaling and breast cancer: polymorphisms and age of onset. $J$ Clin Endocrinol Metab 2003, 88:1653-1657.

11. Piersma D, Berns EMJJ, Verhoef-Post M, Uitterlinden AG, Braakman I, Pols HAP, Themmen APN: A common polymorphism renders the luteinizing hormone receptor protein more active by improving signal peptide function and predicts adverse outcome in breast cancer patients. J Clin Endocrinol Metab 2006, 91:1470-1476.

12. Nakayama $Y$, Wondisford FE, Lash RW, Bale AE, Weintraub BD, Cutler GB Jr, Radovick S: Analysis of gonadotropin-releasing hormone gene structure in families with familial central precocious puberty and idiopathic hypogonadotropic hypogonadism. J Clin Endocrinol Metab 1990, 70:1233-1238.

13. Iwasaki $H, E m i ~ M$, Ezura $Y$, Ishida $R$, Kajita $M$, Kodaira $M$, Yoshida $\mathrm{H}$, Suzuki T, Hosoi T, Inoue S, et al:: Association of a Trp16Ser variation in the gonadotropin releasing hormone signal peptide with bone mineral density, revealed by SNP-dependent PCR typing. Bone 2003, 32:185-190.

14. Smeets-Goevaers CG, Lesusink GL, Papapoulos SE, Maartens LW, Keyzer JJ, Weerdenburg JP, Beijers LM, Zwinderman AH, Knottnerus JA, Pols HA, et al:: The prevalence of low bone mineral density in Dutch perimenopausal women: the Eindhoven perimenopausal osteoporosis study. Osteoporos Int 1998, 8:404-409.

15. Atger M, Misrahi M, Sar S, Le Flem L, Dessen P, Milgrom E: Structure of the human luteinizing hormone-choriogonadotropin receptor gene: unusual promoter and $5^{\prime}$ 'non-coding regions. Mol Cell Endocrinol 1995, 111:113-123

16. Applied Biosystems [http://store.appliedbiosystems.com]

17. Sasieni PD: From genotypes to genes: doubling the sample size. Biometrics 1997, 53:1253-1261.

18. Kaplan EL, Meier P: Nonparametric estimation from incomplete observations. J Am Stat Assoc 1958, 53:457-481.

19. Dean M: Approaches to identify genes for complex human diseases: lessons from Mendelian disorders. Hum Mutat 2003 , 22:261-274.

20. SignalP [http://www.cbs.dtu.dk/services/SignalP]

21. Gründker $C$, Völker $P$, Schulz KD, Emons G: Luteinizing hormone-releasing hormone agonist triptorelin and antagonist cetrorelix inhibit EGF-induced c-fos expression in human gynecological cancers. Gynecol Oncol 2000, 78:194-202.

22. Mangia A, Tommasi S, Reshkin SJ, Simone G, Stea B, Schittulli F, Paradiso A: Gonadotropin releasing hormone receptor expression in primary breast cancer: comparison of immunohistochemical, radioligand and western blot analyses. Oncol Rep 2002, 9:1127-1132.

23. McArdle CA, Franklin J, Green L, Hislop JN: Signalling, cycling and desensitisation of gonadotrophin-releasing hormone receptors. J Endocrinol 2002, 173:1-11.

24. Günthert $A R$, Gründker $C$, Bongertz $T$, Nagy $A$, Schally $A V$, Emons G: Induction of apoptosis by $\mathrm{AN}-152$, a cytotoxic analog of luteinizing hormone-releasing hormone (LHRH), in LHRH-R positive human breast cancer cells is independent of multidrug resistance-1 (MDR-1) system. Breast Cancer Res Treat 2004, 87:255-264.

25. Kottler ML, Starzec A, Carre MC, Lagarde JP, Martin A, Counis R: The genes for gonadotropin-releasing hormone and its receptor are expressed in human breast with fibrocystic disease and cancer. Int J Cancer 1997, 71:595-599.

26. Chen A, Kaganovsky E, Rahimipour S, Ben-Aroya N, Okon E, Koch $\mathrm{Y}$ : Two forms of gonadotropin-releasing hormone (GnRH) are expressed in human breast tissue and overexpressed in breast cancer: a putative mechanism for the antiproliferative effect of GnRH by down-regulation of acidic ribosomal phosphoproteins P1 and P2. Cancer Res 2002, 62:1036-1044.

27. Miller WR, Scott WN, Morris R, Fraser HM, Sharpe RM: Growth of human breast cancer cells inhibited by a luteinizing hormone-releasing hormone agonist. Nature 1985, 313:231-233.

28. Pimstone B, Epstein S, Hamilton SM, LeRoith D, Hendricks S: Metabolic clearance and plasma half disappearance time of exogenous gonadotropin releasing hormone in normal subjects and in patients with liver disease and chronic renal failure. J Clin Endocrinol Metab 1977, 44:356-360.

29. Klijn JGM, Blamey RW, Boccardo F, Tominaga T, Duchateau L, Sylvester R: Combined tamoxifen and luteinizing hormonereleasing hormone (LHRH) agonist versus LHRH agonist alone in premenopausal advanced breast cancer: a meta-analysis of four randomized trials. J Clin Oncol 2001, 19:343-353.

30. Klijn JGM, Beex LV, Mauriac L, van Zijl JA, Veyret C, Wildiers J, Jassem J, Piccart M, Burghouts J, Becquart D, et al.: Combined treatment with buserelin and tamoxifen in premenopausal metastatic breast cancer: a randomized study. J Natl Cancer Inst 2000, 92:903-911.

31. Jonat W, Pritchard KI, Sainsbury R, Klijn JG: Trends in endocrine therapy and chemotherapy for early breast cancer: a focus on the premenopausal patient. J Cancer Res Clin Oncol 2006:1-12.

32. Colozza M, de Azambuja E, Cardoso F, Bernard C, Piccart MJ: Breast cancer: achievements in adjuvant systemic therapies in the pre-genomic era. Oncologist 2006, 11:111-125.

33. Stearns V, Schneider B, Henry NL, Hayes DF, Flockhart DA: Breast cancer treatment and ovarian failure: risk factors and emerging genetic determinants. Nat Rev Cancer 2006, 6:886-893. 